\title{
A series of editorials regarding the question: why is my paper rejected?
}

\section{Série de editoriais objetivando responder à pergunta: porque o meu trabalho é recusado?}

Maria Isabel Toulson Davisson Correia, TCBC-MG ${ }^{1}$ id.

A uthors frequently ask themselves and others, the reason(s) why a manuscript has been rejected, especially, when it has not been sent to peer-review (the scientific critical appraisal/editing process that validates academic work, and helps improve the quality of research). When a paper is upfront rejected by the editor-in-chief, something that accounts, in several journals, for the majority of papers, many reasons justify such decision.

According to Peter Thrower ${ }^{1}$, there are eight reasons he rejects an article: 1 ) it fails the technical screening. This initially phase is usually carried out, in major journals, by editorial managers who check suspected plagiarism, the completeness of the manuscript regarding the conformity with the rules of the journal and the quality of language. Figures and tables are checked to see if they are complete and adequate, and references are reviewed to see if they are in accordance with the text and are mostly new; 2) the manuscript does not fall within the aims and scope of the journal. In this regard, authors are encouraged to check previous numbers and the instructions to authors to make sure they comply with this; 3 ) the paper is incomplete because it does not fully provide important details pertaining the study goal; 4) the methods and results are defective and incomplete, especially when relevant information is missing, such as sample size calculation; 5) the discussion and conclusions cannot be justified on the basis of the rest of the paper, in the case, the arguments are illogical, unstructured or invalid or the data do not support the conclusions; 6) it is simply a small extension of a different paper, often from the same authors (salami publication); 7) it is incomprehensible regarding language, structure, figures etc; 8) it is boring, usually because it is of marginal interest to the field, the study question is of no interest or the readers will not be interested.

Scientific knowledge is translated into clinical practice by manuscript publications, which have had a tremendous increase in the last couple of years ${ }^{2}$, not exactly accompanied by good quality writing ${ }^{3}$. Writing and publishing a manuscript should follow rules that must contemplate ethics in research, the novelty or the reason for the investigation, the quality and clarity of the methods, the confirmation of the findings as well as the discussion pertaining that particular data compared to other authors' who have addressed a similar topic or when complete new data are provided, it is absolutely allowed to elucubrate on the potential explanations of those phenomena ${ }^{4}$. The quality of language is also a key element, and omitting needless words is an art that requires training, training and training.

Therefore, the goal of this series of editorials is to provide a few practical information and recommendations, the so called 'hints" to help inexperienced, and maybe also the experienced authors into the art of scientific writing. After all, disseminating knowledge is vital to the healthcare system, to the authors, and in particular to the patients. However, when the quality of the publications is questionable, no one benefits!

1 - Universidade Federal de Minas Gerais, Cirurgia - Belo Horizonte - MG - Brasil. 


\section{REFERENCES}

1. Thower P. Eight reasons I rejected your article. 2012 Sep 12 [cited 2020 May]. In: Elsevier Connect [Internet]. The Netherlands: Elsevier. Available from: https://www.elsevier.com/ connect/8-reasons-i-rejected-your-article.

2. Ioannidis JP. The Mass Production of Redundant, Misleading, and Conflicted
Systematic Reviews and Meta-analyses. Milbank Q. 2016;94(3):485-514.

3. Correia MITD. Nutrition in times of Covid-19, how to trust the deluge of scientific information. Curr Opin Clin Nutr Metab Care. 2020;23(4):288-93.

4. Strunk W, White EB. The elements of style. 4th ed. Needham Heights (MA): Allyn \& Bacon; 1935. 105 p.
Received in: 13/06/2020

Accepted for publication: 15/06/2020

Conflict of interest: no.

Funding source: none.

\section{Mailing address:}

Maria Isabel Toulson Davisson Correia

E-mail: isabel_correia@uol.com.br

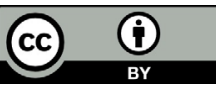

